\title{
A personal dust sampler simulating variable human lung function
}

\author{
R KUCHARSKI \\ From the Department of Air Pollution Effects, Environmental Pollution Abatement Centre, Katowice, \\ Poland
}

ABSTRACT In a prototype of a new personal dust sampling system (PDS) the speed of air sampling in the breathing zone is related to the pulmonary ventilation rate of the wearer, using the correlation between pulmonary ventilation and pulse rate that is monitored by electrodes fastened on the sampler wearer's chest. The method of calibration and the results of dust chamber and field measurements are presented. The prototype of the new sampler was tested in a lead and zinc smelting plant against a routine stationary sampler and typical personal sampler. Personal exposure using all the above mentioned devices has also been assessed, and the PDS gives satisfactory results in use.

At present personal samplers for airborne contaminants are used widely by industrial hygienists in various types of industry in many different countries. $^{1-8}$ There is no doubt that the use of personal dust samplers helps considerably to assess personal exposure when compared with classic methods of sampling. To assess personal exposure better changes in the pulmonary ventilation rate connected with physical work must be taken into account, since this affects the amount of dust penetrating the respiratory tract. 910

This paper presents a system that attempts to improve the assessment of personal exposure by including in the sampling process the factor of changing pulmonary ventilation rate due to change of work effort.

\section{Methods}

DESIGN OF THE SAMPLER AND PRINCIPLE OF ITS OPERATION

The personal dust sampling (PDS) system allows continuous dust sampling in the worker's breathing zone during the whole work shift and automatically compensates for changes in physical effort by following pulmonary ventilation rate. The air is sampled at a variable aspiration rate by a diaphragm pump through a filter situated in the breathing zone of the worker. The pump is powered by a 6-volt motor coupled with silver-zinc batteries. Changing

Received 8 January 1979

Accepted 19 March 1979 the aspiration rate in accordance with pulmonary ventilation is achieved by changing the motor speed, which, in turn, is regulated by changes of voltage given by an electronic regulation unit. The electronic regulation unit counts and transforms the ECG impulses from the heart, which are monitored by electrodes applied to the chest. In this way the increase or decrease in pulse rate controls the change of flow of the sampled air through the filter. When using PVC fibre filters the pump flow variation caused by the filter loading is negligible.

The basis performance data of the apparatus are as follows:

Electrodes

commercially made ECG electrodes of $25 \mathrm{~mm}$ diameter, applied to the body with sticking-plaster and using ECG contact paste.

Electronic control details of the system are described in patent 66340 (Poland).

Motor $\mathrm{U}=6 \cdot 3 \mathrm{~V}$ $\mathrm{n}=7200 \mathrm{rpm}$ $\mathbf{P}=0.8 \mathrm{~W}$.

Pump

Flow rate of the sampler

Total weight

Dimensions about $2.5 \mathrm{~kg}$. $65 \times 125 \times 180 \mathrm{~mm}$. 


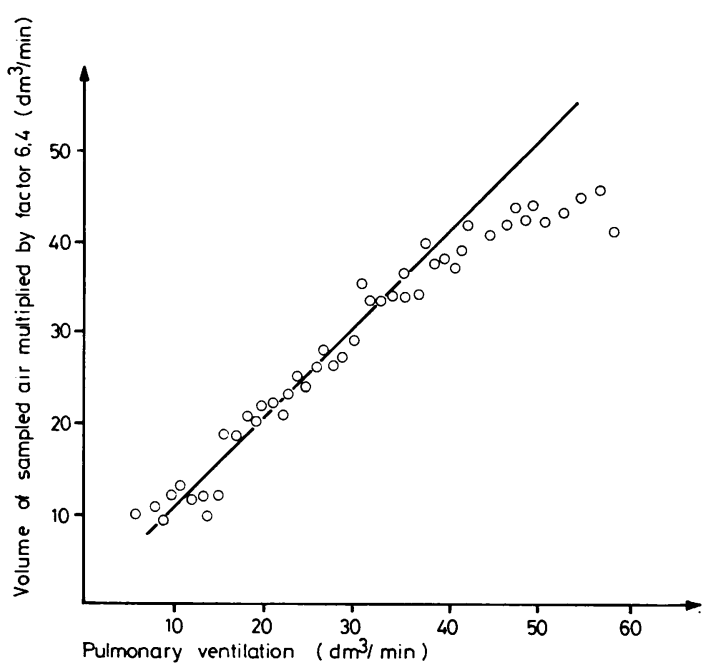

Calibration of personal dust sampler.

A good correlation has been found between the pulse rate and pulmonary ventilation rate..$^{11-13}$ Using this dependence it was possible to correlate sampling rate and pulmonary ventilation of the wearer of the sampler.

The calibration of the sampler using respiratory measurements of 30 men has been completed (figure). The respiration factor: pulmonary ventilation vs sampling rate was established as $6.4 \pm 0.3$ dependent on personal variability.

\section{LABORATORY TESTING OF PDS SYSTEM}

The instrument was calibrated in a dust chamber. Three dust samples were taken simultaneously inside the dust chamber. Two samplers were obtained using the classic sampling set consisting of vacuum pump, gas meter, tubing, and sampling head. A third sample was taken using the PDS. The 30 subjects, aged 17-52 years and weighing $55-97 \mathrm{~kg}$, had to exercise on a bicycle ergometer situated beside the dust chamber. In each case, during a one-hour trial, the loading of the bicycle ergometer was changed periodically to test the operation of the sampler throughout its entire range of aspiration rates. This experimental programme was a simulation of the operation of the personal sampler during normal sampling under different physical work loads. The results of the dust concentration obtained from all samplers differed from the average within a range not greater than $10 \%$ 。

FIELD TESTING OF THE PDS SYSTEM The preliminary industrial trials data for the PDS system were obtained in a lead and zinc smelting plant. Work stations requiring degrees of physical effort were chosen. The area of each work station was about $200 \mathrm{~m}^{2}$.

The experiment was programmed to take into account the following problems:

(a) comparison of static dust sampling with the results obtained from the PDS system;

(b) comparison of static sampler with an ordinary personal sampler ${ }^{14}$; and

(c) immediate assessment of personal exposure by analysing dust retained in a dust respirator used by the wearer of the PDS sampler.

To meet all these requirements both the personal sampler and the dust respirator coupled to a PVC filter were worn simultaneously by one worker. The samples were taken over a period of six hours. Observations were carried out at two work places for $\mathbf{4 0}$ days.

The volume of sampled air was calculated from the counters of both personal dust samplers. The volume of air drawn through the filter of the dust respirator was calculated by multiplying the respiratory factor $(6 \cdot 4)$ by the volume of air pulled into the PDS sampler.

The static sampler was located in the place where the worker remained for the longest duration during his shift. PVC filters were used with each sampler. Dust samples were examined quantitatively for zinc using a polarographic method.

Pulmonary ventilation during work, using physiological standards, ${ }^{12}$ was also assessed further to calculate personal exposure by the classic method, and to compare the results with those obtained from the PDS sampler.

Personal exposure was estimated as follows:

(a) the amount of zinc retained on the filter of the dust respirator was assumed to be an immediate and proper index of exposure;

(b) the content of zinc on the filter of the PDS sampler was multiplied by the respiratory factor; and

(c) the calculation of personal exposure using the results from the ordinary personal dust sampler and static sampler was made in the following way: the concentration of zinc in ambient air, defined by both samplers, was related to the amount of the air that had been ventilated by the respiratory tract of the personal sampler wearer. The total volume of the respired air was calculated using the physiological standards.

Estimated value of personal exposure, calculated by each method, should be about equal to the value obtained from the dust respirator.

If it is assumed that all of the dust samplers working simultaneously are sampling from the 
Comparison of personal exposure assessment methods using " $t$ " test, $n=22, p=0.05$

\begin{tabular}{|c|c|c|c|c|c|c|}
\hline \multirow{3}{*}{$\begin{array}{l}\text { Sampling methods } \\
\text { compared }\end{array}$} & \multicolumn{3}{|c|}{ Work station I } & \multicolumn{3}{|c|}{ Work station II } \\
\hline & \multicolumn{2}{|l|}{ "t" value } & \multirow[t]{2}{*}{ Difference } & \multicolumn{2}{|l|}{ " $t$ " value } & \multirow[t]{2}{*}{ Difference } \\
\hline & Calculated & Critical & & Calculated & Critical & \\
\hline $\begin{array}{l}\mathbf{R} / \mathbf{S S} \\
\mathrm{R} / \mathrm{PDS} \\
\mathbf{R} / \mathbf{P S}\end{array}$ & $\begin{array}{l}3 \cdot 550 \\
0 \cdot 235 \\
2 \cdot 590\end{array}$ & $\begin{array}{l}2 \cdot 074 \\
2 \cdot 074 \\
2 \cdot 074\end{array}$ & $\begin{array}{l}\text { Significant } \\
\text { Not significant } \\
\text { Significant }\end{array}$ & $\begin{array}{l}2 \cdot 370 \\
1 \cdot 010 \\
1 \cdot 857\end{array}$ & $\begin{array}{l}2 \cdot 074 \\
2 \cdot 074 \\
2 \cdot 074\end{array}$ & $\begin{array}{l}\text { Significant } \\
\text { Not significant } \\
\text { Not significant }\end{array}$ \\
\hline
\end{tabular}

$\mathbf{R}=$ respirator; $\mathbf{S S}=$ stationary sampler; $\mathrm{PS}=$ personal sampler PDS = PDS sampler.

same area the differences between the exposure dose calculated from various samplers ought not to be statistically significant.

\section{Results and discussion}

Presuming that the respirator loading is a good measure of personal exposure, the comparison between the exposure calculated from the respirator and other samplers was done using the " $t$ " test.

The table shows no statistically significant differences when comparing personal exposure estimated by means of respirator and PDS at two working stations. Significant differences were found in three of four series of experiments when checking the respirator against a stationary sampler and a personal sampler.

The above results seem to indicate that the accuracy of the personal exposure assessment using the PDS is good when the dust concentration and physical effort of the worker vary over periods of time.

It must be emphasised that because of variable sampling rate the problem of size-selecting sampling when using the PDS still remains unsolved.

I wish to express my thanks to Mr Jerzy Gorgon for his valuable assistance in the design of the PDS prototype.

\section{References}

1 Avy AP, Benarie M, Schmitt K, Winkiel A. Vergleichende Untersuchen an Staubmessgeraten in einer Staubkugel. Staub 1963;23:1-10.

2 Bloor WA, Eardley RE, Dinsdale A. A gravimetric personal dust sampler. Ann Occup Hyg 1968;11:81-7.

${ }^{3}$ Chatterjee BB, Williams MK, Walford J, King E. The location of personal sampler filter heads. $\mathrm{Am}$ Ind $\mathrm{Hyg}$ Assoc J 1969;30:643-5.

${ }^{4}$ Landwehr M. Present trends in dust sampling and MAC values in West Germany. Can Mining Metallurgical Bull 1969;62:454-61.

${ }^{5}$ Maguire BA, Barker D. A gravimetric dust sampling instrument/SIMPEDS/Preliminary underground trials. Ann Occup Hyg 1969;12:197-201.

- Morse KM, Bumsted HE, Janes WC. The validity of gravimetric measurements of respirable coal mine dust. Am Ind Hyg Assoc J 1971;32:104-14.

${ }^{7}$ Sheppard WV. Airborne dust prevention and suppression in British coal mines. Coal Mining Proc 1970;4:64-8.

${ }^{8}$ Siltanen R, Simeček J. Staubuntersuchungen in finnischen Gieserein. Staub 1970;30:147-50.

- Drasche H, Eeckenkamp HW. Mesures des poussières au poste de travail sous l'angle de la médecine du travail. Arch Mal Prof Méd Travail Séc Soc 1971;32: 283-8.

${ }^{10}$ Dutkiewicz T. Chemia toksykologiczna. Warszawa: Państwowy Zakład Wydawnictw Lekarskich, 1969.

11 Åstrand PO. Human physical fitress with special reference to sex and age. Physiol Rev 1956;36:307-55.

12 Lehmann G. Praktische Arbeitsphysiologie. Stuttgart: Georg Thieme, 1962:228-32.

${ }^{13}$ Sharkey BJ. Pulse rate and pulmonary ventilation as predictors of human energy cost. Ergonomics 1966;9: 223-7.

14 Sherwood JR, Greenhalgh DMS. A personal air sampler. Ann Occup Hyg 1960;127:215-22. 